\title{
Exertional dyspnoea in obesity
}

\author{
Vipa Bernhardt ${ }^{1}$ and Tony G. Babb ${ }^{2}$ \\ Number 3 in the Series “Exertional Dyspnoea” \\ Edited by Pierantonio Laveneziana and Piergiuseppe Agostoni
}

\begin{abstract}
Affiliations: ${ }^{1}$ Dept of Health and Human Performance, Texas A\&M University-Commerce, Commerce, TX, USA. ${ }^{2}$ Institute for Exercise and Environmental Medicine, Texas Health Presbyterian Hospital Dallas and UT Southwestern Medical Center, Dallas, TX, USA.
\end{abstract}

Correspondence: Tony G. Babb, Institute for Exercise and Environmental Medicine, 7232 Greenville Ave, Ste 435, Dallas, TX 75231, USA. E-mail: TonyBabbaTexasHealth.org

ABSTRACT The purpose of cardiopulmonary exercise testing (CPET) in the obese person, as in any cardiopulmonary exercise test, is to determine the patient's exercise tolerance, and to help identify and/or distinguish between the various physiological factors that could contribute to exercise intolerance. Unexplained dyspnoea on exertion is a common reason for CPET, but it is an extremely complex symptom to explain. Sometimes obesity is the simple answer by elimination of other possibilities. Thus, distinguishing among multiple clinical causes for exertional dyspnoea depends on the ability to eliminate possibilities while recognising response patterns that are unique to the obese patient. This includes the otherwise healthy obese patient, as well as the obese patient with potentially multiple cardiopulmonary limitations. Despite obvious limitations in lung function, metabolic disease and/or cardiovascular dysfunction, obesity may be the most likely reason for exertional dyspnoea. In this article, we will review the more common cardiopulmonary responses to exercise in the otherwise healthy obese adult with special emphasis on dyspnoea on exertion.

\section{o} @ERSpublications

Obesity alone and/or as a confounding factor may contribute to DOE requiring careful assessment during CPET http://ow.ly/Secp305mId2

\section{Introduction}

The purpose of cardiopulmonary exercise testing (CPET) is to assess a patient's functional capacity, and assess the physiological performance of the cardiovascular and respiratory systems in unison. Unexplained dyspnoea on exertion (DOE) is one of the main symptoms for which a CPET is requested [1]. Exertional dyspnoea can be due to a number of illness-related abnormalities, solely due to deconditioning and/or due to obesity alone [2-4]. Physiological responses to exercise may be completely normal in patients with DOE, or in many cases, patients with severe disease may also be obese, gravely complicating the assessment of exercise limitations and the potential mechanisms of DOE. In this article, we will cover

Other articles in this series: No. 1: Dubé B-P, Agostoni P, Laveneziana P. Exertional dyspnoea in chronic heart failure: the role of the lung and respiratory mechanical factors. Eur Respir Rev 2016; 25: 317-332. No. 2: O’Donnell DE, Elbehairy AF, Faisal A, et al. Exertional dyspnoea in COPD: the clinical utility of cardiopulmonary exercise testing. Eur Respir Rev 2016; 25: 333-347.

Received: Aug 172016 | Accepted after revision: Oct 122016

Support statement: This study was funded by the National Institutes of Health (grant HL096782), King Charitable Foundation Trust, Cain Foundation and Texas Health Presbyterian Hospital Dallas. Funding information for this article has been deposited with the Open Funder Registry.

Conflict of interest: None declared.

Provenance: Submitted article, peer reviewed.

Copyright OERS 2016. ERR articles are open access and distributed under the terms of the Creative Commons Attribution Non-Commercial Licence 4.0. 
CPET to explore and unmask the mechanisms underlying DOE in otherwise healthy obese adults and clinical patients with both disease and obesity.

\section{Approach to CPET for assessing dyspnoea on exertion}

While a maximal incremental (or graded) CPET is the gold standard for determining maximal exercise performance, it is not the best way to assess DOE. Instead, in order to properly evaluate the relationship between exercise and dyspnoea, a steady-state (or at least constant-load) exercise test should be conducted. This is because the temporal dynamics of respiratory sensations are slower to establish than those for physiological responses $[5,6]$. Thus, an adequate amount of time at a given exercise intensity should be provided, such that the respiratory sensation(s) reach a temporal steady state. This cannot be assured if the exercise time is short, if the exercise intensity is high, or if the exercise intensity is changed quickly as is the case during an incremental exercise test. In an incremental exercise test, the intensity and quality of respiratory sensations the subjects rate can change as the exercise intensity and ventilatory demands change quickly. So at any particular incremental work rate, the subjects could be rating less respiratory sensations than at the same work rate at steady state. Our data (unpublished combined with published) in 124 otherwise healthy, obese women support this notion of latency of respiratory symptoms (figure 1).

Thus, our long-standing approach to clinical exercise testing is to first perform two submaximal, constant-load stages on the cycle ergometer, followed by the graded maximal test after a short break (figure 2). One submaximal stage should "theoretically" fall below the lactate threshold in order to avoid any additional confounding factors that could alter respiratory sensations, such as increased lactate, and one stage should fall near lactate threshold. Since we don't have the opportunity to test patients in advance due to laboratory and patient availability, we questioned the patients regarding their exercise habits, exercise limitations, symptoms during exertion and regular physical activities to help us select appropriate exercise work rates. We also examined age and sex predicted values for maximal heart rate, peak oxygen uptake and maximal work rate, which helped us in the selection of appropriate submaximal work rates. With experience, this process actually works fairly well since lactate values for our cardiopulmonary laboratory average around $2 \mathrm{mmol} \cdot \mathrm{L}^{-1}$ for the first stage and 3-3.5 mmol. $\mathrm{L}^{-1}$ for the second stage. These constant-load stages will allow the clinician or investigator to examine the responses to exercise at work rates that are representative of activities of daily living.

Steady-state exercise testing is not a new concept. JonEs [9] proposed a series of exercise tests, termed stages 1-4, for clinical exercise testing in the 1970s. The steady-state exercise tests were conducted to examine inter-relationships among metabolism, cardiac output and pulmonary gas exchange [9]. As JonEs [9] performed the maximal test first, he could choose the submaximal workloads of approximately one-third and two-thirds of the maximum power output achieved. Our approach to assessment begins with the submaximal tests, which requires the exercise physiologist to estimate appropriate workloads based on the patients symptoms during exertion and exercise activity history (i.e. individualised testing or "precision" medicine). Performing the submaximal tests first also prepares the patient for the all-out effort required for the maximal test and accustoms them to the potentially uncomfortable mouthpiece, the rebreathing technique for cardiac output, stationary cycling and the timing of certain measurements (e.g. lactate sampling, pulmonary function assessments, ratings of perceived exertion and breathlessness). This approach also allows the patient to recover somewhat in preparation of the maximal effort while also consulting with the staff and physician regarding symptoms or instructions for the next phase of testing. A familiarisation test would be best for this but time constraints for a busy clinical laboratory does not allow for this type of testing.

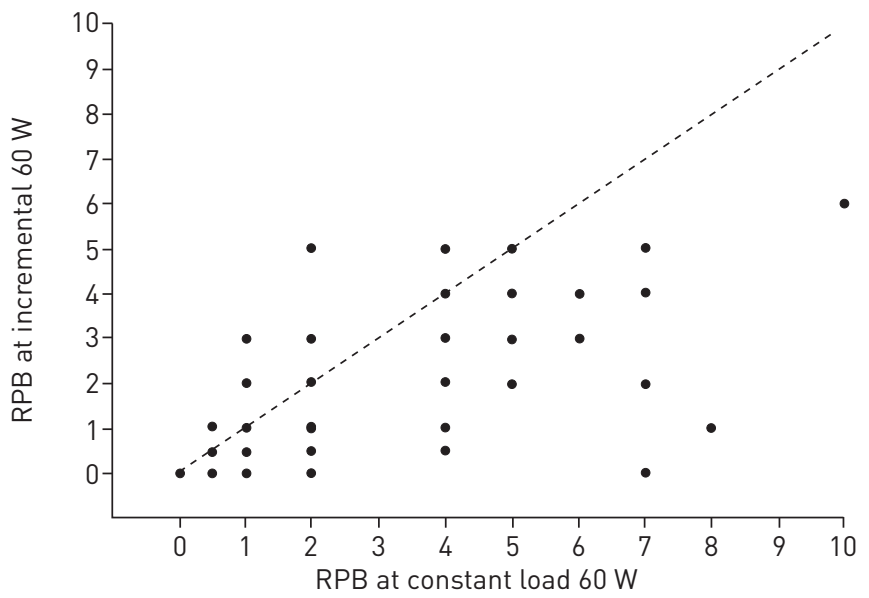

FIGURE 1 Each dot represents a participant's rating $(n=124)$ during the constant load submaximal exercise test at $60 \mathrm{~W}$ and during the incremental maximal exercise test at the $60 \mathrm{~W}$ stage. Dashed line represents line of identity. RPB: ratings of perceived breathlessness (Borg scale 0-10). Data from [7, 8] and unpublished data. 
FIGURE 2 Representation of a commonly used cardiopulmonary exercise testing protocol in our clinical patients showing two steady-state levels (4-5 min each), a rest period ( $15 \mathrm{~min})$ and the incremental increase to volitional exhaustion (1 min each level until max).

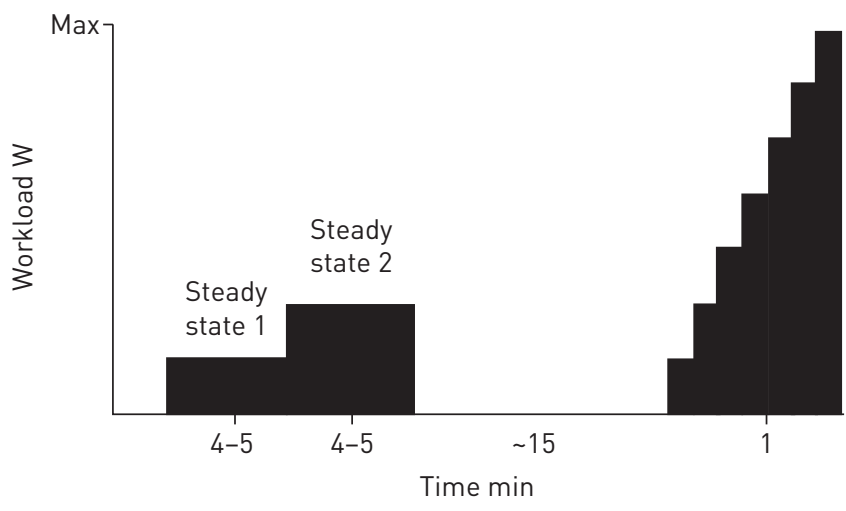

The workload of the submaximal tests is individualised to the patient and is chosen based on patient's symptoms and the activities where they occur. The patients who are referred to our clinical laboratory for assessment of dyspnoea on exertion can be quite diverse; heart, respiratory, pulmonary hypertension and transplant patients, but also athletes. Thus, depending on the patient, steady-state 1 is typically between 10-40 W (average $25 \mathrm{~W}$ ) and steady-state 2 between 20-80 W (average around $50 \mathrm{~W}$ ). During steady-state 1 , heart rate $(\sim 50 \%$ of predicted maximal heart rate), respiratory exchange rate $(\sim 0.9)$, and lactate $\left(2 \mathrm{mmol} \cdot \mathrm{L}^{-1}\right)$ are carefully observed. Typically, the workload for steady-state 2 is double that of steady-state 1 , unless the previously mentioned values are over- or underestimated. After a rest period, the maximal test is conducted in 1-min stages of 10 or $20 \mathrm{~W}$ increments (figure 2). Gas exchange and inspiratory capacity (for flow-volume loops) are measured at each stage and cardiac output is measured at peak exercise while maintaining pedalling.

For our research participants, we used a similar testing approach of one constant-load stage at a fixed work rate of $60 \mathrm{~W}$ in women and $105 \mathrm{~W}$ in men, followed by the incremental maximal test. These participants are usually younger (20-45 years), otherwise healthy and obese.

\section{CPET in obesity}

Obesity

The prevalence of obesity in the USA has reached epidemic levels. The most recent data show that $37.7 \%$ of adults (35.2\% of men and $40.5 \%$ of women) are considered obese as categorised by a body mass index $(\mathrm{BMI})$ of $\geqslant 30 \mathrm{~kg} \cdot \mathrm{m}^{-2}$ [10]. Similarly, $38.5 \%$ of adults $\geqslant 60$ years of age are obese [10]; thus a large population of potential patients will have obesity as a confounding factor during CPET. Obesity is associated with an increased risk for many serious diseases and health conditions, including hypertension, type 2 diabetes, coronary heart disease, sleep apnoea and mental illness [11-14]. Obese patients incur much higher medical care costs (including inpatient, outpatient and prescription drug costs) compared with non-obese individuals totalling about $\$ 147$ billion in the USA in 2008 [15]. While mild obesity (i.e. $\mathrm{BMI}<35 \mathrm{~kg} \cdot \mathrm{m}^{-2}$ ) is not associated with a reduction in life expectancy, the higher BMI categories are [16].

Of course, calculation of BMI can only provide a rough estimate of body composition, although it is often used as a surrogate for body fat percentage. This practice should be avoided especially in women, as data from hydrodensitometry and dual-energy X-ray absorptiometry show that body fat percentage values are much higher than BMI in women [7, 8, 17]. Although obese adults exhibit much greater fat mass than non-obese adults (both in absolute values and relative to total body weight) the relative distribution of fat can be remarkably similar $[18,19]$. Most notably, visceral fat, which is generally associated with a higher risk for cardiometabolic diseases [20-23], accounted for similar percentages of total body fat in these subjects $(8 \pm 3 \%$ versus $10 \pm 4 \%$ in lean and obese men, respectively, and $5 \pm 3 \%$ versus $5 \pm 1 \%$ in lean and obese women, respectively), although the absolute fat mass was almost four times greater [18]. These data indicate that weight gain occurs fairly evenly across the whole body and not just in certain areas. Likewise, weight loss does not change fat distribution since fat mass is lost from all body regions, including chest, abdominal, visceral, subcutaneous and peripheral areas [24].

Physical activity is an important component in the prevention and treatment of obesity [25], but many obese individuals do not participate in regular exercise due to exertional dyspnoea [26]. Several obesity-related limitations (both at rest and during exercise) could contribute to exertional dyspnoea, even in the absence of comorbidities, as discussed in the following sections. The CPET approach is a good method to assess multiple systems during the stress of exercise to examine potential causes for DOE in otherwise healthy adults. 
Respiratory function at rest

Before conducting any CPET for DOE, we believe it is important to assess resting pulmonary function, especially in the obese person who may have only minor changes in lung function or much greater than would be expected change in lung function based on BMI. The effects of obesity on respiratory function at rest, including changes in lung volume, respiratory system mechanics and expiratory flow, are well established and have been reported in several reviews $[27,28]$. Briefly, functional residual capacity (FRC) and expiratory reserve volume are reduced, while inspiratory capacity is increased, thus maintaining a relatively normal total lung capacity [29]. The reduction in FRC increases the prevalence and severity of expiratory flow limitation [30-32]. In addition, total respiratory system compliance is reduced [33, 34] and the oxygen cost of breathing in increased [35-37]. Weight loss reverses most changes in lung volumes and oxygen cost of breathing [38, 39], indicating that the excess fat weight on the chest wall is the main factor for the alterations.

\section{Respiratory function during exercise}

The alterations in lung volumes at rest carry over to changes in respiratory function during exercise. Due to the reduced FRC (end-expiratory lung volume), resting and exercise tidal breathing occurs at low operational lung volumes $[18,40]$ where there is increased resistive loading of the respiratory system. Thus, the main increase in tidal volume has to be achieved via increases of end-inspiratory lung volume, not a decrease in end-expiratory lung volume as is the case in healthy non-obese individuals. The increased work of the inspiratory muscles to expand the lungs and chest wall against the fat load [36, 41, 42], as well as the reduced lung and chest wall compliance [34], may contribute to the increased oxygen cost of breathing during exercise [43-45] and the characteristic shallow and rapid breathing pattern [30, 46] of obese individuals. Another consequence of low operational lung volumes during exercise is the risk of developing expiratory flow limitation, which in turn could increase breathlessness symptoms [47, 48]. However, in a recent study of 29 moderately obese women (BMI $36 \mathrm{~kg} \cdot \mathrm{m}^{-2}$ ) only four exhibited expiratory flow limitation [39].

Ventilation during exercise is higher in obese compared with non-obese individuals for a given work rate [30, 46, 49-52]. This is mainly due to an increased metabolic demand of moving heavier limbs during exercise, but the increased oxygen cost of breathing could also play a small role [39]. In this regard, we recently showed that moderate weight loss of $8 \%(\sim 7 \mathrm{~kg})$ reduced the percentage of respiratory muscle contribution to total body oxygen uptake $\left(V^{\prime} \mathrm{O}_{2}\right)$ by $26 \%$, which accounted for almost half of the reduction in $V^{\prime} \mathrm{O}_{2}$ [39]. Although ventilation is increased in obesity, when taking into account the increased oxygen uptake and carbon dioxide output, ventilation and the ventilatory response to exercise appear to be normal in otherwise healthy obese, morbidly obese, as well as obese patients with sleep apnoea $[30,46,50,53]$ and arterial carbon dioxide tension is maintained within normal limits $[54,55]$.

\section{Exercise capacity}

Traditionally, obesity has been associated with decreased cardiorespiratory fitness as measured by peak $V^{\prime} \mathrm{O}_{2}$ during CPET. However, our studies in otherwise healthy obese adults show that the majority do not show cardiorespiratory deconditioning [7, 18, 40,56-58]. This discrepancy may be due to two factors. 1) The observed lower physical fitness, where the obese are less able to perform activities of daily living and aerobic exercise. 2) The misleading "normalisation" of $V^{\prime} \mathrm{O}_{2}$ by the person's body weight (i.e. in $\mathrm{mL} \cdot \mathrm{min}^{-1} \cdot \mathrm{kg}^{-1}$ ), which severely penalises the heavier individual and inappropriately classifies them into poorer cardiorespiratory fitness categories according to the guidelines published by the American College of Sports Medicine [59, 60]. Instead, a predicted value (based on height and estimated normal weight) may be a more unbiased interpretation of cardiorespiratory fitness, especially in the obese population, because the cardiovascular system capacity is not related to weight [61]. Thus, the most recent clinical recommendations for cardiorespiratory fitness interpretation by the European Association for Cardiovascular Prevention and Rehabilitation and the American Heart Association [1] include the reporting of $V^{\prime} \mathrm{O}_{2}$ as a percent of the predicted $V^{\prime} \mathrm{O}_{2}$ based on prediction equations developed by WASSERMAN et al. [62] and HANSEN et al. [63]. This equation has been shown to be the best when assessing cardiorespiratory fitness in obese men, whereas an improved equation for obese women should be explored [60].

\section{DOE in obesity}

Prevalence of DOE in obesity

DOE is an often-stated symptom in obesity. Based on data from the Third National Health and Nutrition Examination Survey [64], obese participants were 2.66 times more likely to experience dyspnoea when walking up a hill compared with matched non-obese participants [65]. Many patients referred for CPET due to unexplained dyspnoea are overweight/obese with no significant coexisting conditions [2, 3, 66]. Additionally, overweight/obese individuals who have an increased perception of exercise difficulty are more likely to regain weight following a weight loss intervention [67]. 
Any of the above-mentioned limitations could result in a heightened perception of breathlessness in the obese, especially during physical activity when ventilation is increased. Ofri et al. [30] showed that even though minute ventilation during an incremental cycling test was higher in the obese compared with non-obese adults, the intensity of breathlessness at any given minute ventilation was not. These results would suggest that breathlessness is dependent only on minute ventilation (and $V^{\prime} \mathrm{O}_{2}$ ). However, as we have shown in several studies, not all obese adults experience dyspnoea on exertion $[7,24,43,44,58]$. In our studies, the prevalence of DOE in otherwise healthy obese adults is $\sim 37-44 \%$, as defined by a rating of perceived breathlessness $(\mathrm{RPB}) \geqslant 4$ (i.e. "somewhat strong" or higher) on the $0-10$ Borg scale after 6 min of constant-load cycling at 60 or $105 \mathrm{~W}$ for women or men, respectively. Re-analysing our data from 171 obese women showed $41 \%$ as experiencing DOE, $33 \%$ with no or mild DOE (RPB $\leqslant 2$ ), and $26 \%$ with moderate $\mathrm{DOE}(\mathrm{RPB}=3)$ during submaximal exercise (figure 3). In contrast, almost none of the non-obese adults studied rated an RPB of $\geqslant 4$ [68]. The findings of OFIR et al. [30] of a similar minute ventilation/ dyspnoea slope during an incremental test in obese versus non-obese women align with our results in obese women without DOE, but not in women with DOE who showed higher dyspnoea ratings at any given minute ventilation (figure 4).

Two main questions arise. 1) What makes some otherwise healthy obese individuals more breathless during exercise than others? 2) How can DOE be alleviated in these individuals?

\section{Differences between subgroups of obese: with DOE versus without DOE}

To investigate the mechanism(s) of why some otherwise healthy obese women become dyspnoeic during exercise and others do not we assessed potential differences in body composition, fat distribution, pulmonary function, work of breathing, cardiorespiratory measures and subjective respiratory symptom perception. Except for the perceptual measurement, none of the other above mentioned comprehensive assessments showed any marked significant differences between the groups of obese women with and without DOE $[7,8]$. The groups differed in their responses to the qualitative aspect of their dyspnoea; namely an increased sensation of the work of breathing [7]. Interestingly, however, the oxygen cost of breathing is similar between the groups [69] and retrospective analysis (figure 5). In addition, unpleasantness and anxiety related to breathlessness were rated significantly higher following the submaximal exercise in the obese women with DOE compared with those without DOE, indicating that both the sensory (i.e. intensity) and affective (i.e. emotional response) dimension of dyspnoea are aberrantly increased in these women [70]. The differences between obese women with and without DOE seem to be psychophysiological in nature, rather than physiological; possible mechanism(s) are discussed below.

\section{Calorie reduction or aerobic exercise training as potential treatments of DOE}

Diet and physical activity are the two main methods recommended to the obese individual in order to achieve a negative caloric balance. Increasing daily physical activity may be particularly difficult for the person who becomes dyspnoeic with even mild-to-moderate intensity exercise. We tested the effects of weight loss (via caloric reduction diet only) and improved cardiorespiratory fitness (via aerobic exercise training without weight loss) on DOE in otherwise healthy obese women $[8,24]$. Both treatments by themselves markedly ameliorated breathlessness during submaximal cycling exercise at $60 \mathrm{~W}$; however, the mechanism of this improvement is unclear as there were no significant correlations with any accompanying physiological changes in body composition, fat distribution, pulmonary function, work of breathing or cardiorespiratory measures $[16,24]$. It is possible that the improvement in DOE could be due to psychophysiological mechanism(s), which should be investigated in future studies.

FIGURE 3 Frequency distribution of ratings of perceived breathlessness (RPB) in 171 otherwise healthy obese women. Data from $[15,16]$ and unpublished data.

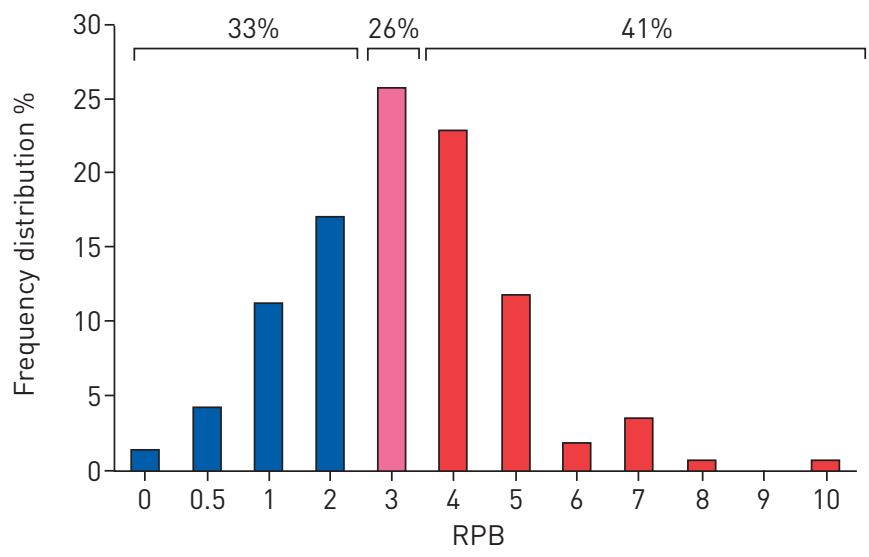




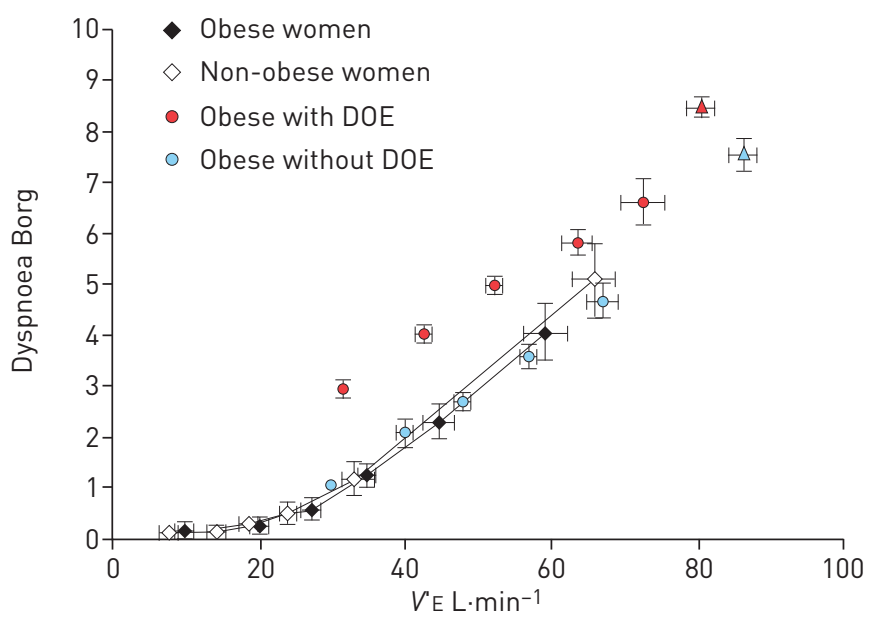

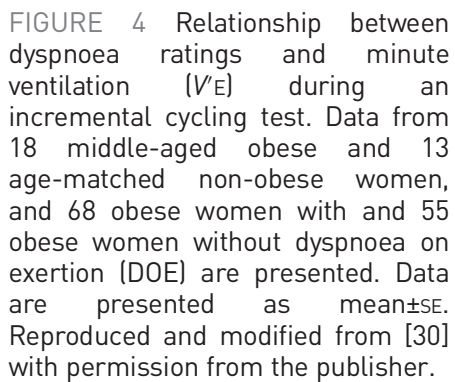

Potential psychophysiological mechanisms of DOE

Several psychophysiological factors could contribute to the increased DOE in some otherwise healthy obese adults (figure 6). The perception of dyspnoea involves conscious recognition and interpretation of respiratory stimuli and their meaning [71, 72]. Respiratory sensations are believed to reach consciousness via a subcortical threshold-gated mechanism; only stimuli with large enough intensities will generate cortical awareness $[73,74]$. Dyspnoea usually originates with a physiological impairment. Obesity-related limitations could lead to the stimulation of afferent receptors and the transmission of afferent information to the cerebral cortex, where the sensation is perceived as uncomfortable or unpleasant [72]. It is unclear why afferent information reaches consciousness in some obese adults and not others since the alterations (if any) in body composition, respiratory function and cardiovascular conditioning are very similar among obese adults with and without DOE, as detailed above. However, obese adults with DOE could have increased afferent feedback, increased ascending corollary discharge from the respiratory control centre and/or a change in the "respiratory gate" (figure 6) [74, 75]. This neural respiratory gate, possibly located at the subcortical level, is thought to be a mechanism to filter out redundant or insignificant respiratory inputs before they reach cortical awareness; only a large enough respiratory stimulus would be consciously perceived by the individual [76]. The threshold for generating awareness of respiratory stimuli can be influenced by modifiers, such as current mood state, negative emotions and/or prior experiences, thus controlling whether consciousness is obtained, inhibited or habituated (figure 6) [75, 77-79]. For example, CHAN et al. [80] have shown that anxiety leads to a decreased respiratory gating, meaning that more stimuli reach consciousness and the stimulus is over perceived. Similarly, negative emotions reduced respiratory gating [79], while positive emotions increased it [81]. In our studies, both anxiety and unpleasantness were rated higher in the women with DOE [70], so it stands to reason that these women could have an aberrant reduction in respiratory gating leading to the heightened perception in dyspnoea during exercise. If, indeed, negative emotions affect the neural processing of respiratory stimuli, this could pave the way to a change in the treatment of DOE in obesity. While diet and regular aerobic exercise can reduce DOE, a psychological intervention targeted to eliminate negative emotions associated with breathlessness may potentially have similar effects. These speculations will have to be tested in future studies.

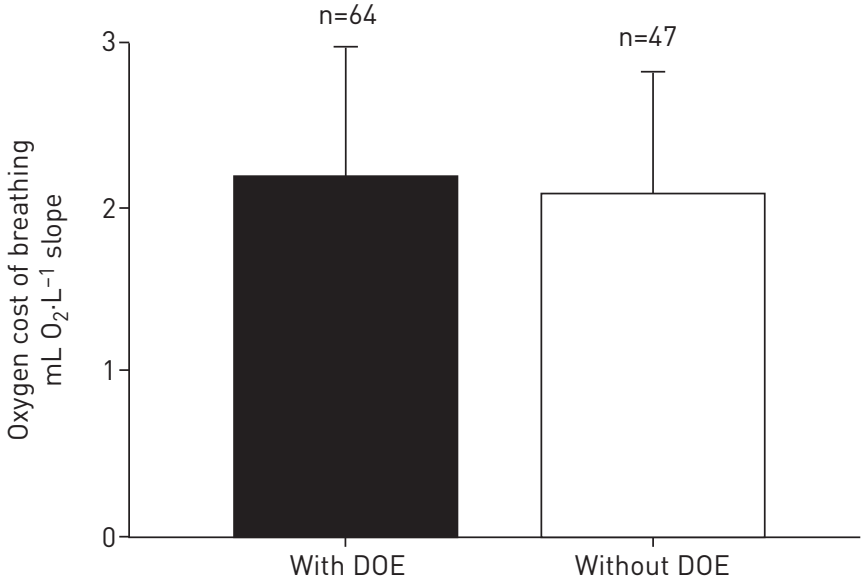

FIGURE 5 Retrospective analysis showing that the oxygen cost of breathing is similar between obese women with and without dyspnoea on exertion (DOE) ( $p>0.05)$. 


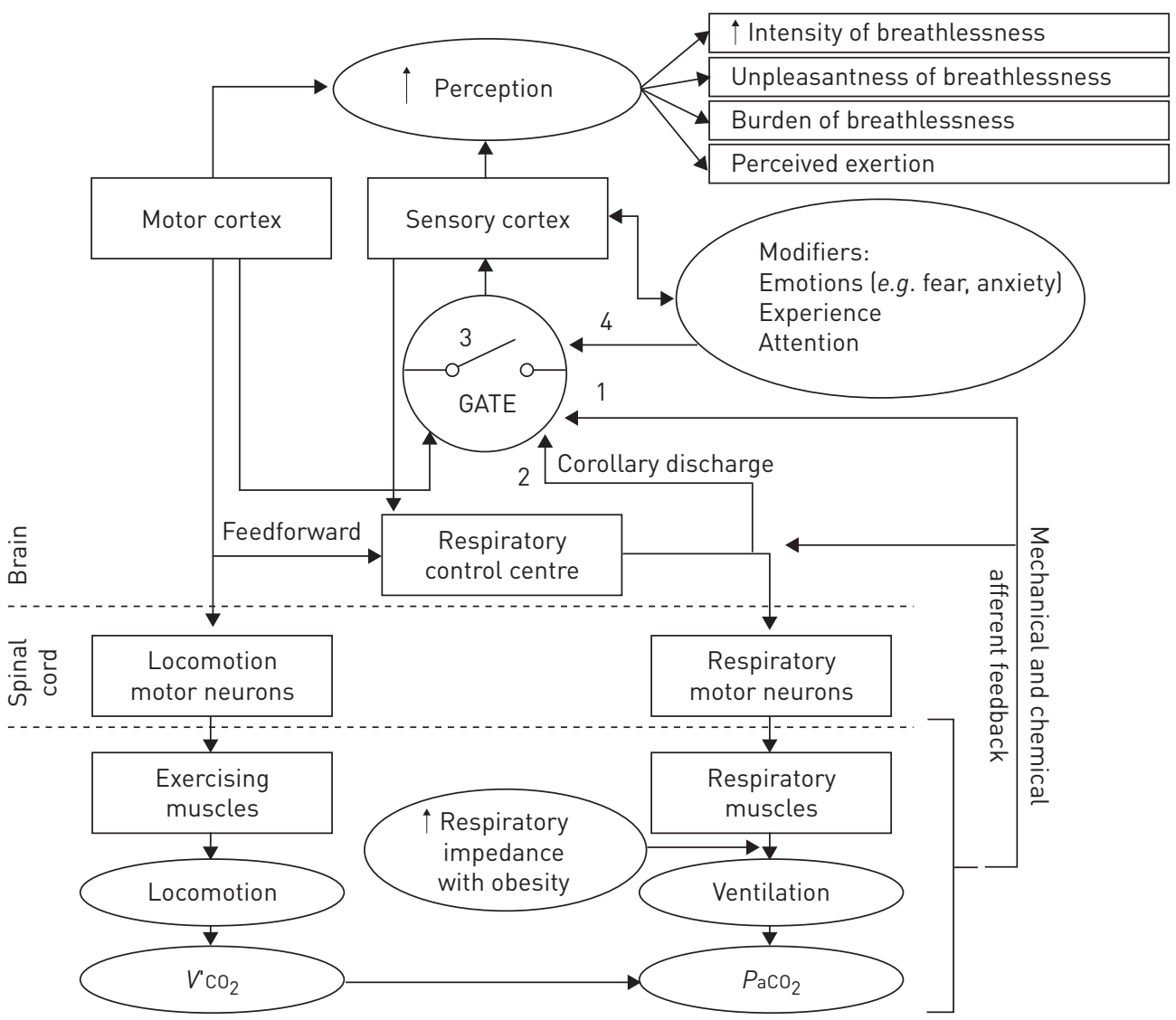

FIGURE 6 Schematic diagram of the potential psychophysiological mechanism of perception of breathlessness in obese adults with dyspnoea on exertion. 1: increased afferent feedback; 2: increased corollary discharge from the respiratory control centre; 3 : decreased gating threshold for sensory transmission; 4: decreased or increased input from gating modifiers. $V^{\prime} \mathrm{O}_{2}$ : oxygen uptake; $\mathrm{PaCO}_{2}$ : arterial carbon dioxide tension. Reproduced from [24] with permission from the publisher.

\section{CPET in the obese patient}

Other papers in this series on the use of CPET to explore the mechanisms underlying DOE will address diseases states. However, it is good to remember that, as stated above, many patients with illness will also present with obesity, thus confounding diagnosis. Unmasking the reason for DOE will be problematic, as several factors could play a role. In our cardiopulmonary clinic since 2013 we have seen approximately 121 referral patients for DOE alone. Of these patients, with a variety of diseases or multiple disease states, $27 \%$ had obesity listed as the primary contributing factor for the DOE and in $12 \%$ of the patients obesity was listed as a secondary factor contributing to DOE (unpublished data). Thus, in roughly 39\% of these 121 patients, obesity was a factor in their DOE, which is similar to the prevalence of otherwise healthy obese adults who experience DOE as presented above. We suggest that obesity may be a factor in many patients regardless of disease state or severity.

\section{Conclusion}

In summary, DOE is highly prevalent not only in obese patient populations, but also in otherwise healthy obese adults. CPET in combination with steady-state exercise measurements can help to identify causes or at least eliminate other factors contributing to DOE in patients. In the absence of any physiological differences in otherwise healthy obese adults with or without DOE, we have to look for possible psychophysiological mechanisms that could be responsible for the increased perception of breathlessness.

\section{References}

1 Guazzi M, Arena R, Halle M, et al. 2016 focused update: clinical recommendations for cardiopulmonary exercise testing data assessment in specific patient populations. Circulation 2016; 133: e694-e711.

2 Simons SO, Dubbelink TO, Heijdra YF. Explaining the unexplained: cardiopulmonary exercise testing in the evaluation of chronic unexplained dyspnea. Am J Respir Crit Care Med 2014; 189: A1788.

3 Martinez FJ, Stanopoulos I, Acero R, et al. Graded comprehensive cardiopulmonary exercise testing in the evaluation of dyspnea unexplained by routine evaluation. Chest 1994; 105: 168-174. 
Pratter MR, Abouzgheib W, Akers S, et al. An algorithmic approach to chronic dyspnea. Respir Med 2011; 105: 1014-1021.

5 Banzett RB. Dynamic response characteristics of $\mathrm{CO}_{2}$-induced air hunger. Respir Physiol 1996; 105 : 47-55.

6 Moosavi SH, Banzett RB, Butler JP. Time course of air hunger mirrors the biphasic ventilatory response to hypoxia. J Appl Physiol 2004; 97: 2098-2103.

7 Bernhardt V, Babb TG. Respiratory symptom perception differs in obese women with strong or mild breathlessness during constant-load exercise. Chest 2014; 145: 361-369.

8 Bernhardt V, Stickford JL, Bhammar DM, et al. Aerobic exercise training without weight loss reduces dyspnea on exertion in obese women. Respir Physiol Neurobiol 2016; 221: 64-70.

9 Jones NL. Clinical exercise testing. 3rd Edn. Philadelphia, WB Saunders Co., 1988.

10 Flegal KM, Kruszon-Moran D, Carroll MD, et al. Trends in obesity among adults in the United States, 2005 to 2014. JAMA 2016; 315: 2284-2291.

11 Jensen MD, Ryan DH, Apovian CM, et al. 2013 AHA/ACC/TOS guideline for the management of overweight and obesity in adults. J Am Coll Cardiol 2014; 63: 2985-3023.

12 Luppino FS, de Wit LM, Bouvy PF, et al. Overweight, obesity, and depression: a systematic review and meta-analysis of longitudinal studies. Arch Gen Psychiatry 2010; 67: 220-229.

13 Must A, Spadano J, Coakley EH, et al. The disease burden associated with overweight and obesity. JAMA 1999; 282: 1523-1529.

14 Mokdad AH, Ford ES, Bowman BA, et al. Prevalence of obesity, diabetes, and obesity-related health risk factors, 2001. JAMA 2003; 289: 76-79.

15 Finkelstein EA, Trogdon JG, Cohen JW, et al. Annual medical spending attributable to obesity: payer- and service-specific estimates. Health Aff (Millwood) 2009; 28: w822-w831.

16 Finkelstein EA, Brown DS, Wrage LA, et al. Individual and aggregate years-of-life-lost associated with overweight and obesity. Obesity (Silver Spring) 2010; 18: 333-339.

17 Heo M, Faith MS, Pietrobelli A, et al. Percentage of body fat cutoffs by sex, age, and race-ethnicity in the US adult population from NHANES 1999-2004. Am J Clin Nutr 2012; 95: 594-602.

18 Babb TG, Wyrick BL, DeLorey DS, et al. Fat distribution and end-expiratory lung volume in lean and obese men and women. Chest 2008; 134: 704-711.

19 Babb TG, Haller SF, Bernhardt V, et al. Regional body volumes in nonobese and obese women and men. FASEB J 2012; 26: 877 .

20 Neeland IJ, Turer AT, Ayers CR, et al. Dysfunctional adiposity and the risk of prediabetes and type 2 diabetes in obese adults. JAMA 2012; 308: 1150-1159.

21 Chandra A, Neeland IJ, Berry JD, et al. The relationship of body mass and fat distribution with incident hypertension: observations from the Dallas heart study. J Am Coll Cardiol 2014; 64: 997-1002.

22 Neeland IJ, Turer AT, Ayers CR, et al. Body fat distribution and incident cardiovascular disease in obese adults. J Am Coll Cardiol 2015; 65: 2150-2151.

23 Britton KA, Massaro JM, Murabito JM, et al. Body fat distribution, incident cardiovascular disease, cancer, and all-cause mortality. J Am Coll Cardiol 2013; 62: 921-925.

24 Bernhardt V, Babb TG. Weight loss reduces dyspnea on exertion in obese women. Respir Physiol Neurobiol 2014; 204: 86-92.

25 Pavlou KN, Krey S, Steffee WP. Exercise as an adjunct to weight loss and maintenance in moderately obese subjects. Am J Clin Nutr 1989; 49: 5 Suppl., 1115-1123.

26 Scano G, Stendardi L, Bruni GI. The respiratory muscles in eucapnic obesity: their role in dyspnea. Respir Med 2009; 103: 1276-1285.

27 Salome CM, King GG, Berend N. Physiology of obesity and effects on lung function. J Appl Physiol 2010; 108: $206-211$.

28 Littleton SW. Impact of obesity on respiratory function. Respirology 2012; 17: 43-49.

29 Jones RL, Nzekwu MM. The effects of body mass index on lung volumes. Chest 2006; 130: 827-833.

30 Ofir D, Laveneziana P, Webb KA, et al. Ventilatory and perceptual responses to cycle exercise in obese women. J Appl Physiol 2007; 102: 2217-2226.

31 Pankow W, Podszus T, Gutheil T, et al. Expiratory flow limitation and intrinsic positive end-expiratory pressure in obesity. J Appl Physiol 1998; 85: 1236-1243.

32 Ferretti A, Giampiccolo P, Cavalli A, et al. Expiratory flow limitation and orthopnea in massively obese subjects. Chest 2001; 119: 1401-1408.

33 Naimark A, Cherniack RM. Compliance of the respiratory system and its components in health and obesity. J Appl Physiol 1960; 15: 377-382.

34 Pelosi P, Croci M, Ravagnan I, et al. Total respiratory system, lung, and chest wall mechanics in sedated-paralyzed postoperative morbidly obese patients. Chest 1996; 109: 144-151.

35 Sharp JT, Henry JP, Sweany SK, et al. The total work of breathing in normal and obese men. J Clin Invest 1964; 43: 728-739.

36 Kress JP, Pohlman AS, Alverdy J, et al. The impact of morbid obesity on oxygen cost of breathing $\left(V_{\mathrm{O}_{2 \mathrm{RESP}}}\right)$ at rest. Am J Respir Crit Care Med 1999; 160: 883-886.

37 Chlif M, Keochkerian D, Choquet D, et al. Effects of obesity on breathing pattern, ventilatory neural drive and mechanics. Respir Physiol Neurobiol 2009; 168: 198-202.

38 Babb TG, Wyrick BL, Chase PJ, et al. Weight loss via diet and exercise improves exercise breathing mechanics in obese men. Chest 2011; 140: 454-460.

39 Bhammar DM, Stickford JL, Bernhardt V, et al. Effect of weight loss on operational lung volumes and oxygen cost of breathing in obese women. Int J Obes (Lond) 2016; 40: 998-1004.

40 Babb TG, DeLorey DS, Wyrick BL, et al. Mild obesity does not limit change in end-expiratory lung volume during cycling in young women. J Appl Physiol 2002; 92: 2483-2490.

41 Milic-Emili J, Orzalesi MM. Mechanical work of breathing during maximal voluntary ventilation. J Appl Physiol 1998; 85: 254-258.

42 Cherniack RM. Respiratory effects of obesity. Can Med Assoc J 1958; 80: 613-616.

43 Babb TG, Ranasinghe KG, Comeau LA, et al. Dyspnea on exertion in obese women: association with an increased oxygen cost of breathing. Am J Respir Crit Care Med 2008; 178: 116-123. 
44 Bernhardt V, Wood HE, Moran RB, et al. Dyspnea on exertion in obese men. Respir Physiol Neurobiol 2013; 185: 241-248.

45 Lorenzo S, Babb TG. Ventilatory responses at peak exercise in endurance-trained obese adults. Chest 2013; 144: $1330-1339$.

46 Babb TG, Korzick D, Meador M, et al. Ventilatory response of moderately obese women to submaximal exercise. Int J Obes 1991; 15: 59-65.

47 Mahadev S, Farah CS, King GG, et al. Obesity, expiratory flow limitation and asthma symptoms. Pulm Pharmacol Ther 2013; 26: 438-443.

48 Tantucci C. Expiratory flow limitation definition, mechanisms, methods, and significance. Pulm Med 2013; 2013: 749860.

49 Dempsey JA, Reddan W, Balke B, et al. Work capacity determinants and physiologic cost of weight-supported work in obesity. J Appl Physiol 1966; 21: 1815-1820.

50 Whipp BJ, Davis JA. The ventilatory stress of exercise in obesity. Am Rev Respir Dis 1984; 129: S90-S92.

51 Salvadori A, Fanari P, Tovaglieri I, et al. Ventilation and its control during incremental exercise in obesity. Respiration 2008; 75: 26-33.

52 Romagnoli I, Laveneziana P, Clini EM, et al. Role of hyperinflation vs. deflation on dyspnoea in severely to extremely obese subjects. Acta Physiol (Oxf) 2008; 193: 393-402.

53 Bernhardt V, Bassett JT, Moran RB, et al. Short-term modulation of the ventilatory response to exercise is preserved in obstructive sleep apnea. FASEB J 2016; 30: Suppl 1, 1261.

54 Bernhardt V, Lorenzo S, Babb TG, et al. Corrected end-tidal $P_{\mathrm{CO}_{2}}$ accurately estimates $P_{\mathrm{aCO}} \mathrm{C}_{2}$ at rest and during exercise in morbidly obese adults. Chest 2013; 143: 471-477.

55 Zavorsky GS, Hoffman SL. Pulmonary gas exchange in the morbidly obese. Obes Rev 2008; 9: 326-339.

56 Babb TG, Buskirk ER, Hodgson JL. Exercise end-expiratory lung volumes in lean and moderately obese women. Int J Obes 1989; 13: 11-19.

57 DeLorey DS, Wyrick BL, Babb TG. Mild-to-moderate obesity: implications for respiratory mechanics at rest and during exercise in young men. Int J Obes (Lond) 2005; 29: 1039-1047.

58 Bernhardt V, Bhammar DM, Stickford JS, et al. Aerobic exercise training without weight loss improves dyspnea on exertion in obese women. Respir Physiol Neurobiol 2016; 221: 64-70.

59 American College of Sports Medicine. ACSM's guidelines for exercise testing and prescription. 9th Edn. Baltimore, Lippincott Williams \& Wilkins, 2013.

60 Lorenzo S, Babb TG. Quantification of cardiorespiratory fitness in healthy nonobese and obese men and women. Chest 2012; 141: 1031-1039.

61 Younes M. Interpretation of clinical exercise testing in respiratory disease. Clin Chest Med 1984; 5: 189-206.

62 Wasserman K, Hansen JE, Sue DY, et al., eds. Principles of exercise testing and interpretation. 4th Edn. Philadelphia, Lippincott Williams \& Wilkins, 2005.

63 Hansen JE, Sue DY, Wasserman K. Predicted values for clinical exercise testing. Am Rev Respir Dis 1984; 129: S49-S55.

64 Plan and operation of the Third National Health And Nutrition Examination Survey, 1988-94. National Center for Health Statistics. Vital Health Stat 1 (32). 1994.

65 Sin DD, Jones RL, Man SF. Obesity is a risk factor for dyspnea but not for airflow obstruction. Arch Intern Med 2002; 162: 1477-1481.

66 James P, Mangera Z, Isse S, et al. The role of obesity in unexplained breathlessness and exercise intolerance evaluated by cardio-pulmonary exercise tests (CPET). Thorax 2012; 67: A81.

67 Brock DW, Chandler-Laney PC, Alvarez JA, et al. Perception of exercise difficulty predicts weight regain in formerly overweight women. Obesity (Silver Spring) 2010; 18: 982-986.

68 Lorenzo S, Babb TG. Oxygen cost of breathing and breathlessness during exercise in nonobese women and men. Med Sci Sports Exerc 2012; 44: 1043-1048.

69 Bernhardt V, Moran RB, Bassett JT, et al. Breathlessness, but not oxygen cost of breathing, is higher during voluntary hyperpnea in obese women with $v s$ without dyspnea on exertion. Am J Respir Crit Care Med 2014; 189: A5038.

70 Marines-Price R, Bernhardt V, Bhammar DM, et al. Unpleasantness and negative emotions related to dyspnea on exertion in obese women. FASEB J 2016; 30: Suppl 1, 1288.

71 O'Donnell DE, Banzett RB, Carrieri-Kohlman V, et al. Pathophysiology of dyspnea in chronic obstructive pulmonary disease: a roundtable. Proc Am Thorac Soc 2007; 4: 145-168.

72 Parshall MB, Schwartzstein RM, Adams L, et al. An official American Thoracic Society statement: update on the mechanisms, assessment, and management of dyspnea. Am J Respir Crit Care Med 2012; 185: 435-452.

73 Davenport P, Reep R. Cerebral cortex and respiration. In: Dempsey J, Pack A, eds. Regulation of Breathing. New York, Dekker, 1995; pp. 362-388.

74 Chan PY, Davenport PW. Respiratory-related evoked potential measures of respiratory sensory gating. $J$ Appl Physiol 2008; 105: 1106-1113.

75 von Leupoldt A, Chan PY, Esser RW, et al. Emotions and neural processing of respiratory sensations investigated with respiratory-related evoked potentials. Psychosom Med 2013; 75: 244-252.

76 Cromwell HC, Mears RP, Wan L, et al. Sensory gating: a translational effort from basic to clinical science. Clin EEG Neurosci 2008; 39: 69-72.

77 von Leupoldt A, Bradley MM, Lang PJ, et al. Neural processing of respiratory sensations when breathing becomes more difficult and unpleasant. Front Physiol 2010; 1: 144.

78 von Leupoldt A, Vovk A, Bradley MM, et al. Habituation in neural processing and subjective perception of respiratory sensations. Psychophysiology 2011; 48: 808-812.

79 Chenivesse C, Chan PY, Tsai HW, et al. Negative emotional stimulation decreases respiratory sensory gating in healthy humans. Respir Physiol Neurobiol 2014; 204: 50-57.

80 Chan PY, von Leupoldt A, Bradley MM, et al. The effect of anxiety on respiratory sensory gating measured by respiratory-related evoked potentials. Biol Psychol 2012; 91: 185-189.

81 Chan PY, Cheng CH, Jhu YJ, et al. Being anxious, thinking positively: the effect of emotional context on respiratory sensory gating. Front Physiol 2016; 7: 19. 